NASA/TM-2001-211292

AIAA-2000-3855

Solid Hydrogen Experiments for Atomic Propellants

Bryan Palaszewski

Glenn Research Center, Cleveland, Ohio 
Since its founding, NASA has been dedicated to the advancement of aeronautics and space science. The NASA Scientific and Technical Information (STI) Program Office plays a key part in helping NASA maintain this important role.

The NASA STI Program Office is operated by Langley Research Center, the Lead Center for NASA's scientific and technical information. The NASA STI Program Office provides access to the NASA STI Database, the largest collection of aeronautical and space science STI in the world. The Program Office is also NASA's institutional mechanism for disseminating the results of its research and development activities. These results are published by NASA in the NASA STI Report Series, which includes the following report types:

- TECHNICAL PUBLICATION. Reports of completed research or a major significant phase of research that present the results of NASA programs and include extensive data or theoretical analysis. Includes compilations of significant scientific and technical data and information deemed to be of continuing reference value. NASA's counterpart of peerreviewed formal professional papers but has less stringent limitations on manuscript length and extent of graphic presentations.

- TECHNICAL MEMORANDUM. Scientific and technical findings that are preliminary or of specialized interest, e.g., quick release reports, working papers, and bibliographies that contain minimal annotation. Does not contain extensive analysis.

- CONTRACTOR REPORT. Scientific and technical findings by NASA-sponsored contractors and grantees.
- CONFERENCE PUBLICATION. Collected papers from scientific and technical conferences, symposia, seminars, or other meetings sponsored or cosponsored by NASA.

- SPECIAL PUBLICATION. Scientific, technical, or historical information from NASA programs, projects, and missions, often concerned with subjects having substantial public interest.

- TECHNICAL TRANSLATION. Englishlanguage translations of foreign scientific and technical material pertinent to NASA's mission.

Specialized services that complement the STI Program Office's diverse offerings include creating custom thesauri, building customized data bases, organizing and publishing research results ... even providing videos.

For more information about the NASA STI Program Office, see the following:

- Access the NASA STI Program Home Page at http://www.sti.nasa.gov

- E-mail your question via the Internet to help@sti.nasa.gov

- Fax your question to the NASA Access Help Desk at 301-621-0134

- Telephone the NASA Access Help Desk at 301-621-0390

- Write to: NASA Access Help Desk NASA Center for AeroSpace Information 7121 Standard Drive Hanover, MD 21076 


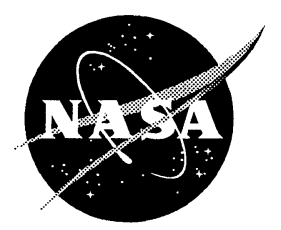

\section{Solid Hydrogen Experiments for Atomic Propellants}

Bryan Palaszewski

Glenn Research Center, Cleveland, Ohio

Prepared for the

36th Joint Propulsion Conference and Exhibit cosponsored by the AIAA, ASME, SAE, and ASEE

Huntsville, Alabama, July 16-19, 2000

National Aeronautics and Space Administration

Glenn Research Center 


\section{Acknowledgments}

I would like to thank the people who assisted in the construction and execution of the experiments conducted at NASA Glenn Research Center: Maureen Kudlac, Henry Speier, Joan Hoopes, Ernie Bell, Donald Metcalf, and Robert Vanek. Thanks to Hugh Aylward and Quentin Schwinn for the image capturing and initial particle size estimates. I would also like to thank John Cole, head of Space Transportation Research (STR) aspects of the

NASA Advanced Space Transportation Program (ASTP), led by NASA Marshall Space Flight Center. Extensive cooperation with the USAF Research Laboratory (Edwards, CA) was also a critical part of this testing. Amy Davis of Hampshire College, Amherst, MA provided reviews of and comments on the video images.

Available from

NASA Center for Aerospace Information 7121 Standard Drive

Hanover, MD 21076
National Technical Information Service 5285 Port Royal Road Springfield, VA 22100 


\title{
SOLID HYDROGEN EXPERIMENTS FOR ATOMIC PROPELLANTS
}

\author{
Bryan Palaszewski \\ National Aeronautics and Space Administration \\ Glenn Research Center \\ Cleveland, Ohio 44135 \\ 216-977-7493 Voice \\ 216-433-5802 FAX \\ bryan.a.palaszewski@grc.nasa.gov \\ Fuels and Space Propellants Web Site \\ http://www.grc.nasa.gov/WWW/TU/launch/foctopsb.htm
}

\begin{abstract}
This paper illustrates experiments that were conducted on the formation of solid hydrogen particles in liquid helium. Solid particles of hydrogen were frozen in liquid helium, and observed with a video camera. The solid hydrogen particle sizes, their molecular structure transitions, and their agglomeration times were estimated. Particle sizes of 1.8 to $4.6 \mathrm{~mm}$ ( 0.07 to $0.18 \mathrm{in}$.) were measured. The particle agglomeration times were 0.5 to 11 minutes, depending on the loading of particles in the dewar. These experiments are the first step toward visually characterizing these particles, and allow designers to understand what issues must be addressed in atomic propellant feed system designs for future aerospace vehicles.
\end{abstract}

\section{NOMENCLATURE}

$\begin{array}{ll}\text { ASTP } & \text { Advanced Space Transportation } \\ & \text { Program } \\ \text { DOE } & \text { Department of Energy } \\ \text { FCC } & \text { Face centered cubic } \\ \text { FOV } & \text { Field of view } \\ \text { GLOW } & \text { Gross lift off weight } \\ \text { GRC } & \text { Glenn Research Center (formerly } \\ & \text { known as Lewis) } \\ \text { H } & \text { Atomic hydrogen } \\ \text { HCP } & \text { Hexagonal close pack } \\ \mathrm{H}_{2} & \text { Molecular Hydrogen } \\ \text { He } & \text { Helium } \\ \text { LLNL } & \text { Lawrence Livermore National } \\ & \text { Laboratory } \\ \text { NASA } & \text { National Aeronautics and Space } \\ & \text { Administration } \\ \text { O/F } & \text { Oxidizer to fuel ratio } \\ \text { SMIRF } & \text { Supplemental Multilayer Insulation } \\ & \text { Research Facility } \\ \text { STR } & \text { Space Transportation Research }\end{array}$

$\begin{array}{ll}\text { USAF } & \text { United States Air Force } \\ \text { wt.\% } & \text { Weight percent } \\ \mathrm{x} / \mathrm{L} & \begin{array}{l}\text { Non-dimensional distance from } \\ \text { dewar lid }\end{array} \\ & \text { INTRODUCTION }\end{array}$

For over 67 years, the promise of atomic propellants has been pursued (Refs. 1-26). Using atoms of boron, carbon, or hydrogen, maintained at cryogenic temperatures, very exciting advances in rocket propellants and airbreathing fuels can be created. Over the decades, many details of the physics of storing such propellants have been analyzed and experimentally determined. Current research is underway with a team from the USAF, NASA, DOE, university, industry, and small business partners (Ref. 2). The extensive data that has been amassed over the last 67 years have shown increasing storage densities for atoms in solid cryogenic storage media, and that there may be future break-throughs that allow the more routine use of atoms for fuels.

\section{WHY ATOMIC PROPELLANTS?}

In the future, rocket and airbreathing propulsion systems may be able to gain great benefits from the enormous power of atomic propellants. Figure 1 shows the potential benefits of atomic hydrogen rockets for Earth launch missions (Refs. 3-8). Using a 15-wt.\% atomic hydrogen fuel, the gross lift off weight (GLOW) of the launch vehicle can be reduced by 50 percent. The baseline rocket and payload weight for the comparison is an oxygen /hydrogen rocket taking $96,000 \mathrm{~kg}$ of payload to Earth orbit. For the atomic hydrogen fuel, the oxidizer to fuel $(\mathrm{O} / \mathrm{F})$ ratio is 0.0. Additional analyses and suggested optimal fuel selections for atomic rocket vehicles are presented in Refs. 3-6. 


\section{SOLID HYDROGEN EXPERIMENTS}

Solid hydrogen particle formation in liquid helium was experimentally investigated.

Experiments were planned to do an initial visual characterization of the particles, observe their formation, and molecular transformations (aging) while in liquid helium. The particle sizes, molecular transformations, and agglomeration times were estimated from video image analyses.

Characterizing solid hydrogen particles is required before any practical propellant feed system can be created. Solid hydrogen particles were selected as a means of storing atomic propellants in future launch vehicles. When storing atoms of boron, carbon, hydrogen, or other atomic materials, a solid hydrogen particle is preferred. Very low temperature $(\mathrm{T}<4 \mathrm{~K})$ cryogenic particles have the ability to stabilize and prevent the atoms from recombining and controlling their lifetime. The particles and the atoms must remain at this low temperature until the fuel is introduced into the engine combustion (or recombination) chamber.

\section{EXPERIMENTAL SETUP}

The experiments were conducted in the Supplemental Multilayer Insulation Research Facility (SMIRF, Ref. 9). The facility has a vacuum tank, into which the experimental setup was placed. The vacuum tank is used to prevent heat leaks and subsequent boiloff of the liquid helium, and the supporting systems maintain the temperature and pressure of the liquid helium bath where the solid particles were created.

The experimental setup included several key components. A small cryogenic dewar was used to contain the helium bath, in which the solid hydrogen particles were formed. The dewar was $711.2 \mathrm{~mm}$ ( 28 in.) in height and had an inside diameter of $295 \mathrm{~mm}$ (11.625 in.). To create the solid hydrogen, liquid hydrogen at a temperature of 14 to $16 \mathrm{~K}$ was used. To contain the liquid hydrogen, a small stainless steel tank was used, which was $152.4 \mathrm{~mm}$ (6 in.) in diameter, and $610 \mathrm{~mm}$ (24 in.) long. To control the hydrogen flow, a precision flow valve was used, and a video camera recorded the particle formation. All of the flow control for the liquid hydrogen, liquid and gaseous helium, and nitrogen purge gases is provided by the SMIRF systems.

In the first step of the hydrogen freezing process, the liquid hydrogen temperature was lowered to 14 to
$16 \mathrm{~K}$. This process allowed the hydrogen to be at a very low temperature, near its freezing point. Comparisons of the heat capacity of helium and the heats of liquefaction and fusion (solidification) of hydrogen led to the selection of conditioning the hydrogen to a very low temperature before releasing it onto the helium surface. Otherwise a large amount of helium would have been used to condense the gaseous hydrogen, liquefy it, and then finally freeze the hydrogen into solid particles. Large clouds of vapor that are created during higher speed hydrogen freezing would have also obscured the formation process, and thwarted efforts to see the final particles.

Solid hydrogen is less dense than helium, so the hydrogen particles floated on the surface, simplifying the particle imaging. In an operational propulsion system, this buoyancy property will be overcome by gelling the helium, thus allowing the hydrogen particles to be suspended in the helium. During the testing, it was noted that the frozen hydrogen particles may also serve as an effective gelling agent for liquid helium.

During the experimental runs, a small amount of liquid hydrogen was dropped onto the surface of the liquid helium. The hydrogen flow rate was selected as being 1/500th liter per second, so as to see the particles form, and eliminate any chance of the relatively warm liquid hydrogen vaporizing all of the liquid helium in the dewar. A small amount of the liquid helium contained in a dewar vaporized as it froze the hydrogen particles.

Figure 2 shows the field of view (FOV) of the camera versus the distance from the dewar lid. Once the liquid helium's free surface is at $\mathrm{x} / \mathrm{L}=0.40(295.4$ $\mathrm{mm}$, or $11.63 \mathrm{in}$.), the liquid's entire surface is in the FOV. For runs 1, 2, and 3, the helium liquid level was maintained at nearly $559 \mathrm{~mm}$ (22 in.) from the dewar lid (Table A1). This location was chosen based on the knowledge of the field of view of the camera. During runs 4 to 7 , the liquid level was at the levels noted in Table A1, and was typically at $406.4 \mathrm{~mm}$ (16 in.) below the lid. This height was chosen to see the particles with higher magnification, and to see if there were any specific phenomena that were not seen in the wider angle view.

Table I shows the locations of the silicon diodes for the temperature measurements. The diodes have a temperature accuracy of \pm 1 degree $\mathrm{K}$, and they are attached to a non-metallic rake that extended from the dewar lid into the liquid helium. The diodes were mounted on circuit boards. A polycarbonate screw attached the top end of the circuit board to a 
polycarbonate rod. The upper end of the polycarbonate rod was threaded and screwed into the underside of the helium dewar lid.

\begin{tabular}{cc}
$\begin{array}{c}\text { TABLE I.-SILICON DIODE LOCATIONS } \\
\text { IN HELIUM DEWAR }\end{array}$ \\
L, DEWAR = 711.2 mm (28 IN.) \\
\hline Name & $\begin{array}{l}\text { Location below } \\
\text { dewar lid (in.) }\end{array}$ \\
\hline SD4 (lid) & 0 \\
LL1 & 2 \\
LL2 & 4 \\
LL3 & 7 \\
LL4 & 10 \\
LL 5 & 12 \\
LL 6 & 14 \\
LL 7 & 16 \\
LL 8 & 19 \\
LL 9 & 22 \\
\hline
\end{tabular}

The liquid hydrogen that exits the liquid tank is at a temperature of 14 to $16 \mathrm{~K}$, just above it's freezing point. As the liquid hydrogen fell toward the helium surface, it begins to freeze and particles form immediately after hitting the helium surface. Some of the hydrogen appears to freeze as it falls, but some vaporizes as well. The hydrogen was a jet of fluid, with the outer shear layer vaporizing, but the central core remaining liquid for a short time, and finally freezing during the drop, and as it hits the helium surface. Figure 3 shows one of the frames captured from the videotape of the experiment. Tables II and A1 summarize the timing for the experimental runs, where each solid hydrogen formation run began. There was an interval of between 25 and 65 minutes between runs. These time spans were chosen to allow the particles to agglomerate, and to observe any unusual or unexpected properties. A more detailed listing of the events from each run is provided in Appendix A. Also, the hydrogen temperatures prior to the hydrogen release are listing in Appendix A. The small particles were allowed to float on the helium surface for at least 25 minutes before adding more hydrogen. During that 25 minute minimum time span, they began to seek each other out, agglomerate into a larger collection of particles, and minimize their surface energy as they float on the helium. The particles also turned from clear or translucent crystals to cloudy crystals, implying a transition from face centered cubic (FCC) to hexagonal close pack (HCP) molecule packing
(Ref. 10). After allowing the first batch of particles to form over 3 experimental runs, we agitated the helium surface, and saw that the particle quickly broke up into their original smaller components. The, particles would then again begin to agglomerate. Additional flows of liquid hydrogen were frozen on the liquid helium surface, and a larger and larger mass of particles was observed.

During the fall of the hydrogen onto the helium, some of the hydrogen went into the gas phase. Small clouds of hydrogen can be seen forming about the stream of hydrogen falling onto the free surface. Additional instrumentation will be needed to assess the total mass of hydrogen that is in the gas phase versus the solid particles. The temperature profiles of the dewar may shed light on the amount of gas formed, and a thermal and mass balance analysis can be conducted to more accurately measure the distribution of hydrogen gas and solid hydrogen in the dewar. A mass spectrometer can be used to determine the mass of hydrogen in the helium gas above the liquid helium.

\section{TABLE II.-SOLID HYDROGEN VIDEO EVENT TIMING}

Prior to the first run, the helium level is between 19 and 22 in. below the lid.
$13: 36: 27$
$14: 13: 35$
14:55:02
The 1st drop begins. The 2nd drop begins. The 3rd drop begins.

A new helium level is selected. The helium level is now between 12 and $14 \mathrm{in}$. below the lid.
$15: 59: 34$

17:00:50

$17: 25: 51$

17:58:51
The 4th drop begins. The 5th drop begins. The 6th drop begins. The 7th drop begins.

\section{SOLID HYDROGEN TESTING RESULTS}

Three major observations resulted from these solid hydrogen particle runs: particle sizes, agglomeration times, and the molecular transitions of the particles. Additional observations had to do with the thermal profile and stratification in the helium dewar, and the operational difficulties that were overcome with the test rig and setup. 


\section{$\underline{\text { Particle sizes }}$}

The solid hydrogen particles were analyzed by digitizing the video images, and measuring the sizes of the particles. These images are provided in Appendix B. The particle size measurements were corrected for the actual size of the particles using these equations:

$\mathrm{D}$, particle $=\mathrm{D}$, measured $\mathrm{x}$

$$
\text { (D, dewar / D, image FOV) }
$$

$\mathrm{D}$, particle $=\quad$ Actual particle diameter (in.)

$\mathrm{D}$, measured $\quad$ Measured particle diameter (in.)

D, dewar Dewar diameter (in.)

D, image FOV Image diameter field of view (in.)

Appendix A contains the raw data of the video observations. These data are the raw measurements of the particle and agglomeration sizes from the video observations. All of the observations were done with a black and white video camera, with a 56 degree field of view. The lighting of the helium surface was with a fiber optic lighting system. The helium free surface was not always completely illuminated, especially for runs 4 to 7 . The indirect illumination of the reflected light from the polished dewar surfaces allowed light to illuminate the shadows surrounding the lit free surface.

Figure 4 shows the solid hydrogen particle sizes (D, particle). These particle sizes were the smallest particles that formed during the initial freezing of the hydrogen. Overall, the initial formed particles were 1.8 to $4.6 \mathrm{~mm}(0.07$ to $0.18 \mathrm{in}$.) in diameter. In this testing, no control was placed on the particle formation, other than the helium and hydrogen temperature and pressure and the flow rate of the hydrogen. The simple freezing process is somewhat random, and the particle will vary in size simply due to the random breakup of the stream of hydrogen that fell onto the helium during the freezing process. The other measurement variation of the particles from the video images that occurred was that all of the particles were not perfectly spherical or elliptical, thus an average size was measured.

\section{$\underline{\text { Molecular transitions }}$}

Figure 5 depicts the transition time for the solid hydrogen. The transition time is the time it took for the solid hydrogen to transition from face centered cubic (FCC) to hexagonal close packed (HCP). Figure 6 shows the relation of the molecular structure with hydrogen temperature (Ref. 10). This transition is noted by the time for the particle to transition from a clear particle to a cloudy particle. Overall, the transition was very fast, taking about 1 minute. However, there were many observations of the particles where they were translucent, and this translucence persisted for many minutes (see Appendix A). This translucence is a function of the temperature of the particles (Ref. 10), and the orientation of them in the agglomeration of particles. While the individual particles may appear cloudy quickly after the formation, the particles were still able to transmit light, and therefore there was a distribution of the FCC and the HCP structure in the particles. Additional analyses should be conducted to determine this distribution in the particles.

\section{Agglomeration times}

Figure 7 illustrates the agglomeration times for the hydrogen particles in the test runs. The typical agglomeration times for the first four runs were from 5 minutes, 18 seconds to 10 minutes, 58 seconds. The differing agglomeration times are caused by the different mass of hydrogen in each drop, the agitation of the helium surface due to localized nucleate boiling, and the location of the hydrogen drop in relation to the agglomerate that was already in the tank. As an example, the agglomeration time on the fifth run was only 27 seconds. This time was so short because the newly introduced of hydrogen fell directly on the previous agglomerate of hydrogen particles. On the 7th run, the agglomeration time is 8 minutes, 24 seconds, and this much longer time is mostly due to the larger mass of hydrogen that was released into the helium dewar.

\section{Thermal stratification}

The temperature profiles for the solid hydrogen test runs is shown in Figures 8, 9, 10, and 11. In all runs, the liquid helium was maintained at $4 \mathrm{~K}$. The freezing of the hydrogen was somewhat countered by the warm helium above the liquid surface. During Runs 1 to 3, as shown in Figure 8, the temperature of the dewar lid was between 184 and $213 \mathrm{~K}$. The lower helium loading led to a higher than expected dewar lid temperature, and hence cause some of the hydrogen to vaporize rather than reach the helium surface. During the test runs, the video showed multiple particles of hydrogen forming, but also a 
small gas cloud about the hydrogen stream falling toward the surface.

Runs 4 to 7 demonstrated significantly lower dewar lid temperatures: 127 to $138 \mathrm{~K}$ (Figure 10). These lower temperatures were due to the higher mass loading of helium in the tank, and the additional thermal conditioning of the tank, allowed by evacuating the tank after filling to the higher loading.

\section{Other Operational Issues}

Freezing of the hydrogen valve occurred over the course of the 7 runs. Table III summarizes the valve cycling required during the runs. On the second and fourth runs, the hydrogen valve was cycled twice and no flow occurred. On the third valve cycling attempt, the hydrogen was released onto the helium surface. The sixth run had one valve opening failure. The valve opened without fail on the first, third, fifth, and seventh run.

\section{TABLE III.-VALVE OPERATION ATTEMPTS FOR LIQUID HYDROGEN}

$\begin{array}{ll}\text { Run number } & \begin{array}{l}\text { Failed valve operations } \\ \text { before flow occurred }\end{array}\end{array}$

\begin{tabular}{ll}
\hline 1 & 0 \\
2 & 2 \\
3 & 0 \\
4 & 2 \\
5 & 0 \\
6 & 1 \\
7 & 0 \\
\hline
\end{tabular}

Tables A1 and IV list the on-time for the hydrogen flow into the helium dewar. During the testing, though the hydrogen valve was opened for a precise amount of time, the flow rate of the hydrogen is not precisely known due to the freezing of the valve. There were several potential problem areas with the valve and its failure to perform and they are being investigated. The valve was a cryogenic valve with an extended stem. The valve was motor operated and the motor was coupled to the valve stem and both of them are in the vacuum chamber. There was a brass bushing at the motor-stem interface. The bushing could be experiencing differential thermal contraction with respect to the stem. There also could be water in the actuator freezing the mechanism. The oil in the stepper motor could be getting viscous, restricting the valve motion. Also, the stepper motor could be over heating in addition to any of the aforementioned effects. The mechanism (or the computer chip) could become hot because the valve is not moving and automatically shuts itself down until it cools off. As a first preventative measure, future testing should add heaters to the valve body to eliminate any condensation or other freezing of the valve.

\section{TABLE IV.-VALVE OPEN (FLOW) TIMES LIQUID HYDROGEN}

$\begin{array}{ll}\text { Run number } & \text { Commanded time } \\ & \text { hydrogen valve open } \\ & \text { for flow (s) }\end{array}$

\begin{tabular}{ll}
\hline 1 & 12 \\
2 & 08 \\
3 & 11 \\
4 & 07 \\
5 & 08 \\
6 & 13 \\
7 & 46 \\
\hline
\end{tabular}

\section{ATOMIC PROPELLANT SYSTEMS IMPLICATIONS}

\section{Feed systems sizing}

The particle sizes that were observed in this testing were millimeter sized. The smallest size created in this testing was about 0.07 in., about $1.8 \mathrm{~mm}$. This particle size seemed to form about 50 percent of the particles created in this simple freezing process, with no significant process control, save for the freezing temperature, and a low flow rate. This formation of small particles bodes well for future formation experiments, and the ultimate propulsion system applications. To create an effective atomic propulsion particle feed system, millimeter sized particles will be needed and were suggested in Ref. 1 . If small particles are easily formed, then this will simplify future propellant manufacturing operations.

\section{CONCLUSIONS}

A series of experiments were conducted to freeze hydrogen particles in liquid helium. These 
experiments are a prelude to creating solid hydrogen particles as a storage medium for atomic boron, carbon, or hydrogen atoms. These experiments with solid hydrogen particles visually characterized the particles, their agglomeration times, and the freezing process effects.

The operations of the apparatus were developed, and visualization of the hydrogen particles was easily obtained. The major difficulty was the freezing of the hydrogen valve, which prevented our efforts to obtain a precise hydrogen mass flow rate. The hydrogen mass flow rate can only be inferred from detailed analyses of the images, and estimating the mass of hydrogen on the helium surface. This valve difficulty should be remedied with small heaters of the valve body to prevent freezing. Also, a mass spectrometer should be employed to determine the mass of hydrogen and helium above the helium free surface. This spectrometer will allow the researcher to estimate the mass of hydrogen that vaporizes and does not reach the helium surface for freezing. The thermal stratification in the helium dewar created a small amount of hydrogen vaporization, and detracts from the particle formation rate. Efforts to reduce this stratification should be made. High loadings of helium in the dewar reduced the stratification, but it was not eliminated.

The solid particles tended to agglomerate within a maximum of 11 minutes, and the agglomerate is very weak. As the hydrogen particles are buoyant in the helium, the agglomerate tends to compact itself into a flat pancake on the surface of the helium. The pancake agglomerate is easily broken apart by reducing the pressure above the liquid. The weak agglomerate implies that the particles can be used as a gelling agent for the liquid helium, as well as a storage medium for the atomic boron, carbon, or hydrogen.

The smallest particle sizes that resulted from the initial freezing experiments were about $1.8 \mathrm{~mm}$. About 50 percent of the particles formed are between 1.8 to $4.6 \mathrm{~mm}$ in diameter. These very small particle sizes are encouraging for future formation experiments, where simpler operations will reduce the costs of production.

The particle freezing process was completed almost immediately after a hydrogen drop, and the molecular structure of the hydrogen tended to change from FCC to HCP structure within 1 minute. This transition must be controlled to allow the deposition of atoms into the solid particles. Higher resolution video will be required to observe the particle formation, and better understand the transition in such small particles.

\section{CONCLUDING REMARKS}

As further developments in atomic physics occur, our research will be able to increase the atom storage density in solid hydrogen. There are many avenues for improving the formation of the particles, and a cost effective way of creating them is being investigated. Particle formation has been conducted in many ways for future fusion energy research. The Lawrence Livermore National Laboratory (LLNL) has conducted extensive testing and fabrication of hydrogen particles for fusion energy research (Refs. 11 to 20). These formation experiments have created particles with precise surface facets that allow the introduction of laser energy into the particle. Such particle formation accuracy may be required for storing high densities of atoms.

The USAF Research Laboratory (Refs. 21 and 22) has conducted work in freezing atomic species and creating solid hydrogen samples for containing these species. Their research has led to a basic understanding of the limits of current physics and what barriers must be overcome to make these atomic fuels and propellants a reality.

Atomic propellants are a shining hope for very high specific impulse rocket and airbreathing vehicles. Many years will be required to develop the capabilities for the high density storage of atoms, the low temperature feed systems, and the rocket engine recombination chambers. However, when these technologies are in hand, the future of aerospace will be revolutionized with the higher specific impulse propulsion systems. Atomic propellants can provide increases of many hundreds of seconds of specific impulse over conventional chemical propulsion, and with it large payload increases of 200 to 400 percent over $\mathrm{O} 2 / \mathrm{H} 2$ rocket propulsion. The future beckons, for a bright new star is forming - atomic propellants.

\section{REFERENCES}

1. Palaszewski, B., "Atomic Hydrogen Propellants: Historical Perspectives and Future Possibilities," NASA-Lewis Research Center, AIAA-93-0244, NASA TM-106053, presented at the 31st AIAA Aerospace Science Meeting, Reno, NV, January 1114, 1993. 
2. Palaszewski, B., Ianovski, L., and Carrick, P., "Propellant Technologies: Far Reaching Benefits for Aeronautical and Space Vehicle Propulsion," in the Special Edition of the AIAA Journal of Propulsion and Power, September/October 1998, pp. 641-648.

3. Palaszewski, B., "Launch Vehicle Performance for Bipropellant Propulsion using Atomic Propellants with Oxygen," NASA Glenn Research Center at Lewis Field, AIAA-99-2837, presented at the 35th AIAA/ASME/SAE Joint Propulsion Conference, Los Angeles, CA, June 1999.

4. Palaszewski, B., "Launch Vehicle Performance with Solid Particle Feed Systems for Atomic Propellants," AIAA-98-3736, NASA/TM-1998208498, presented at the 34th AIAA/ASME/SAE Joint Propulsion Conference, Cleveland, OH, July 1998.

5. Palaszewski, B., "Solid Hydrogen Testing And Analyses For Atomic Rocket Propulsion," presented to the Propulsion Engineering Research Center (PERC) 11th Annual Symposium on Propulsion, The Atherton Hotel, State College, PA, November 18-19, 1999.

6. Palaszewski, B., "Atomic Propellants for Aerospace Propulsion Systems: Solid Hydrogen Experiments and Vehicle Analyses," presented at the 1999 USAF High Energy Density Materials Contractors Conference, Cocoa Beach, FL, June 810, 1999.

7. Palaszewski, B., "Atomic Hydrogen As A Launch Vehicle Propellant," NASA Lewis Research Center, AIAA-90-0715, NASA TM-102459, presented at the 28th AIAA Aerospace Science Meeting, Reno, NV, January 8-11, 1990.

8. Lubell, M., Lue, J., and Palaszewski, B., "LargeBore Superconducting Magnets for High Energy Density Propellant Storage," presented at the 1996 Applied Superconductivity Conference, Pittsburgh, PA, August 25-30, 1996.

9. Dempsey, P., and Stochl, R., "Supplemental Multilayer Insulation Research Facility," NASA Lewis Research Center, NASA TM-106991, July, 1995.

10. Silvera, I., "The Solid Molecular Hydrogens in the Condensed Phase: Fundamentals and Static Properties," Reviews of Modern Physics, Vol. 52, No. 2, Part I, April 1980, pp. 393-452.
11. Sater, J.D., Pipes, J., and Collins, G.W. "Cryogenic D-T Fuel Layers Formed In 1-mm Spheres By Beta-Layering," Report Number UCRLJC-128031-ABS-REV-1, Lawrence Livermore National Laboratory, Target Fabrication Meeting '98, 1998.

12. Collins, G.W., Sanchez, J.J., Bernat, T., Sater, J.D., and Bittner, D., Forming Uniform D-T And D2 Layers For Cryogenic NIF Targets," Report Number UCRL-JC-129969-ABS, Lawrence Livermore National Laboratory, European Conference on Laser Interaction with Matter, 1998

13. Bittner, D.N., Collins, G.W., Monsler, E., and Letts, S., "Forming Uniform HD Layers In Shells Using Infrared Radiation," Livermore National Laboratory, Report Number UCRL-JC-131371, 40th Annual Meeting of the Division of Plasma Physics, New Orleans, LA, November 16-20, 1998.

14. Collins, G.W., Bittner, D.N., Monsler, E., Letts, S., Tiszauer, D., Feit, M., Mapoles, E.R., and Bernat, T. P., "Forming And Smoothing D2 and HD Layers For ICF By Infrared Heating," Lawrence Livermore National Laboratory, Report Number UCRL-JC123596-ABS, European Conference on Laser Interaction with Matter, 24th, Madrid, Spain, June 37, 1996

15. Collins, G.W., Mapoles, E.R., Sanchez, J.J., Bernat, T., Sater, J.D., Bittner, D., Sheliak, J.D., Hoffer, J.K., "Reducing DT Surface Roughness For Cryogenic Ignition Targets," Lawrence Livermore National Laboratory, Report Number UCRL-JC124884-ABS, Annual Meeting of the American Physical Society Division of Plasma Physics, 38th, Denver, CO, November 11-15, 1996.

16. Kozioziemski, B.J., Collins, G.W., and Bernat, T.P., "Single Crystal Growth of Solid D2," Lawrence Livermore National Laboratory, Report Number UCRL-JC-125981-ABS, 1997 March Meeting of the American Physical Society, Kansas City, MO, March 17-21, 1997, 1996.

17. Kozioziemski, B.J., Collins, G.W., Bernat, T.P., Mapoles, E.R., and Unites, W., "Crystal Growth and Roughening Of Solid D2," Lawrence Livermore National Laboratory, Target Fabrication Specialist's Meeting, 11th, Orcas Island, WA, September 8-12, 1996, Report Number UCRL-JC-125121-ABS, Fusion Technology, Vol. 31, pp. 482-484, July 1997. 
18. Bittner, D.N., Collins, G.W., Letts, S., and Monsler, E., "Generation Of Uniform Solid HD Layers Inside Spherical Capsules Using Infrared Illumination," Lawrence Livermore National Laboratory, Report Number UCRL-JC-125140ABS, Conference, Target Fabrication Specialist's Meeting, 11th, Orcas Island, WA, September 8-12, 1996.

19. Bernat, T.P., Collins, G.W., Mapoles, E.R., and Duriez, C., "Heat-Flux Induced Changes To Multicrystalline D2 Surfaces," Lawrence Livermore National Laboratory, Report Number UCRL-JC124261-ABS-REV-1, 39th Annual Meeting of the APS (American Physical Society)/DPP (Division of Plasma Physics), Pittsburgh, PA, November 17-21, 1997.

20. Kozioziemski, B.J., Collins, G.W., and Bernat, T.P., "D2 Crystal Growth and Surface Energy," Lawrence Livermore National Laboratory, Report Number UCRL-JC-130037-ABS, Target

Fabrication Meeting '98, Jackson Hole, Wyoming, April 19-23, 1998.

21. Fajardo, M., "Cryosolid Propellants—The Last "Revolutionary" HEDM Concept," in Berman, $M$. (editor), Proceedings of the High Energy Density Matter (HEDM) Contractors Conference, Scientific Special, June 8-10, 1999, January 2000.

22. Larson, C.W., "Kinetics of Boron Carbon HEDM," in Berman, M. (editor), Proceedings of the High Energy Density Matter (HEDM) Contractors Conference, Scientific Special, June 8-10, 1999, January 2000.
23. Talroze, V.L., Gordon, E.B., Ivanov, B.I., Perminov, A.P., Ponomarev, A.N., "Measurement Of The Hyperfine State Of The Hydrogen Atom As It Interacts In The Gas Phase With CO, SO2, CO2 And N2O Molecules," Akademiia Nauk SSSR Page: vol. 227, Akademiia Nauk SSSR, Doklady, vol. 227, Mar. 11, 1976, pp. 407-410. In Russian. Mar. 11, 1976, pp. 407-410. In Russian.

24. Gordon, E.B., Perminov, A.P., Ivanov, B.I., Matiushenko, V.I., Ponomarev, A.N., and Tal'roze, V.L., "Change In The Hyperfine State Of The Hydrogen Atom During Its Collisions With Unsaturated Hydrocarbon Molecules In The Gaseous State," (Previously cited in issue 23, p. 3317, (Zhurnal Eksperimental'noi i Teoreticheskoi Fiziki, vol. 63, Aug. 1972, pp. 401-406.) Soviet PhysicsJETP, vol. 36, Feb. 1973, pp. 212-215. Translation.

25. Hardy, W.N., Klump, K.N., Schnepp, O., Silvera, I.F. "Optical Phonons In Solid Hydrogen And Deuterium In The Ordered State," Phys. Rev. Letters, Vol. 21, No. 5, July 29, 1968. pp. 291-294.

26. Agosta, C.C., Silvera, I.F, Stoof, H. T.C., and Verhaar, B. J., "Trapping Of Neutral Atoms With Resonant Microwave Radiation," Technische Univ., Few-Body Collisions in a Weakly Interacting Bose Gas," reprinted from Physical Review Letters (American Physical Society), v. 62, no. 20, 15 May 1989 pp. 2361-2364. 
Atomic hydrogen rockets: no helium addition

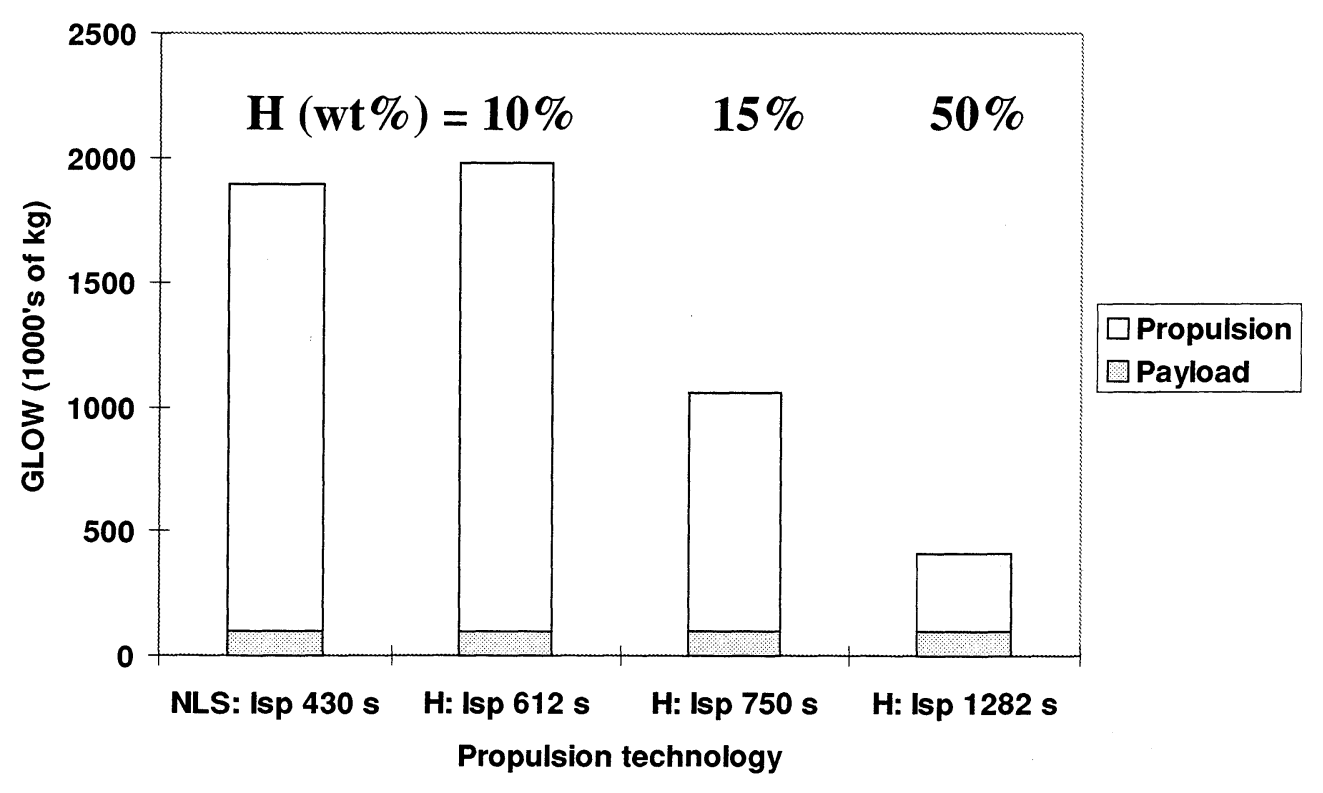

Figure 1.-Atomic hydrogen GLOW for monopropellants: 10-, 15, and 50-wt.\% H.

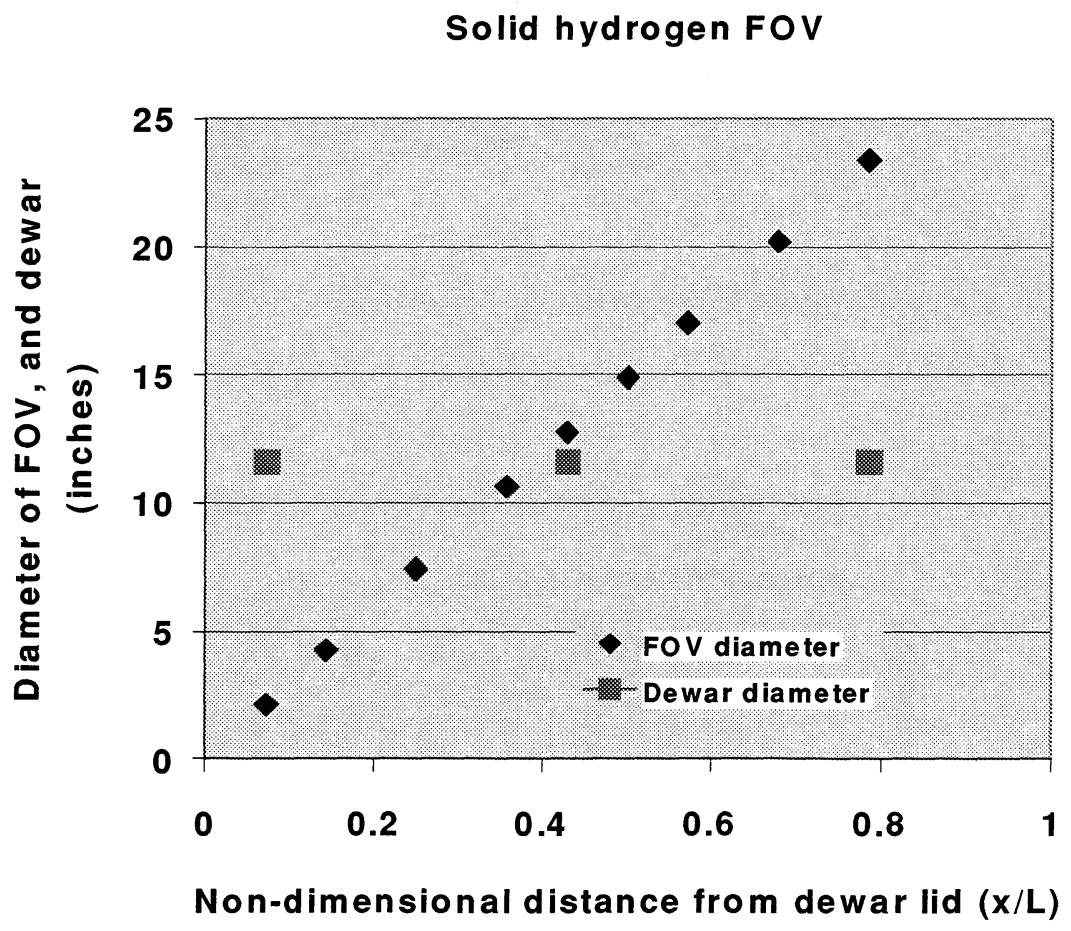

Figure 2.-Solid hydrogen experiment: camera field of view (FOV). 


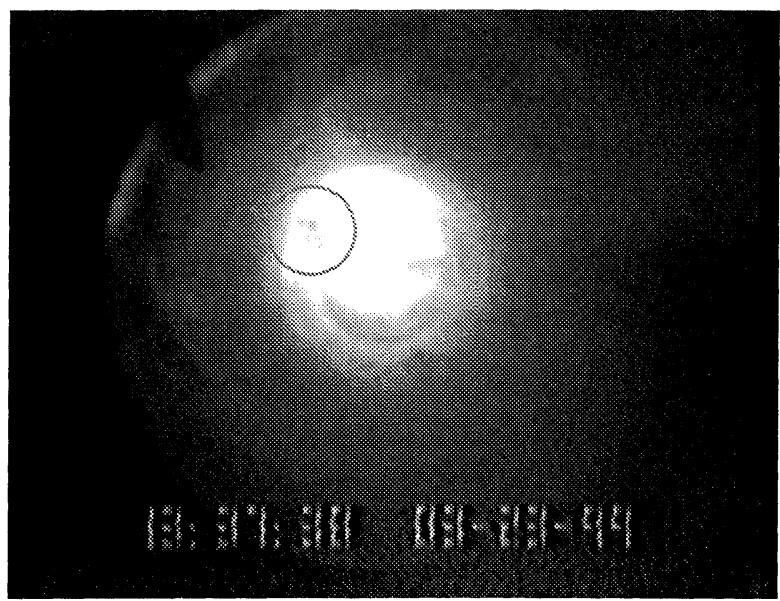

Figure 3.-Solid hydrogen particle formation experiment.

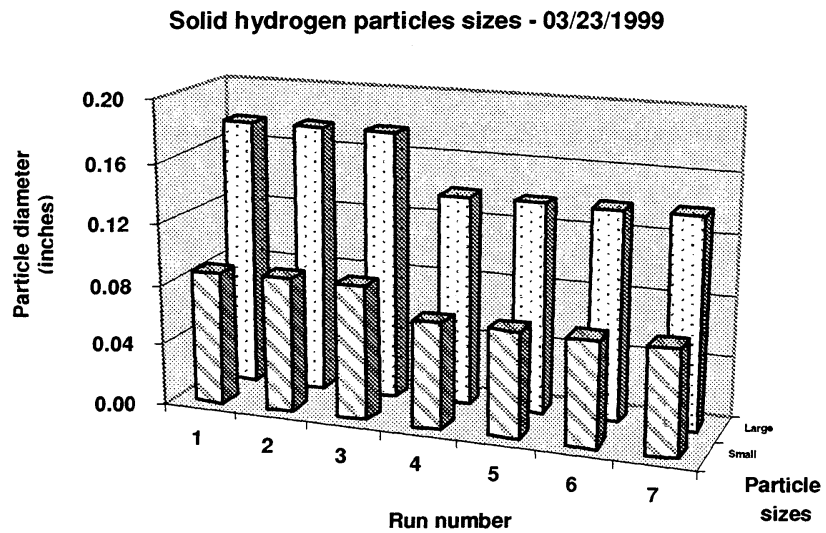

Figure 4.-Solid hydrogen testing - smallest particle sizes: 3/23/1999.

Solid hydrogen molecular transition times: 3/23/1999

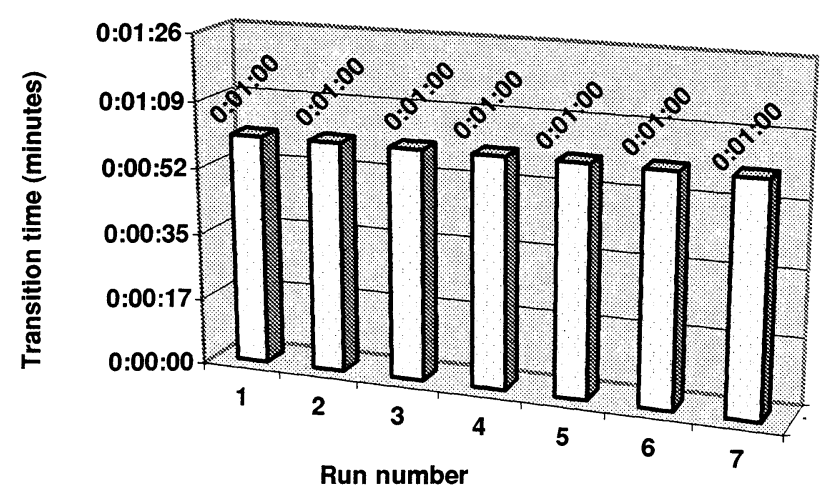

Figure 5.-Solid hydrogen molecular transition times. 


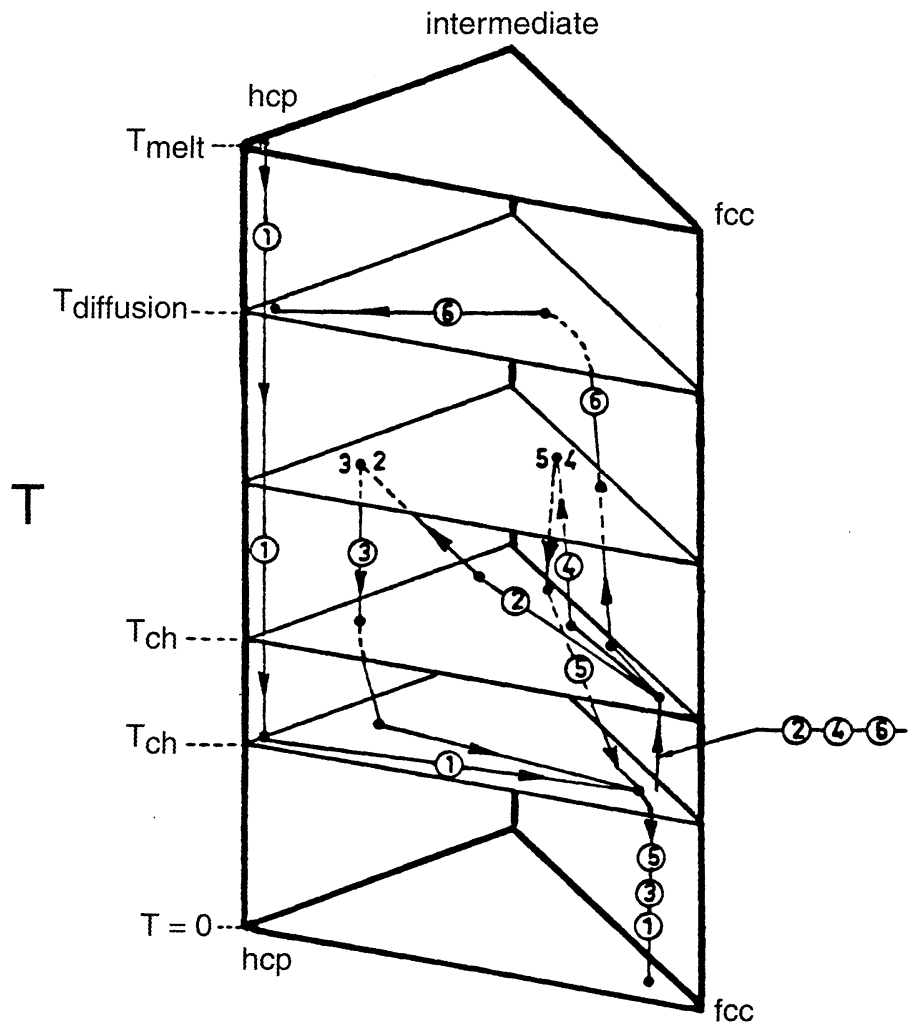

$\mathrm{T}_{\text {melt }}=$ melting temperature $\mathrm{T}_{\text {diffusion }}=$ quantum rotational diffusion temperature $\mathrm{T}_{\mathrm{ch}}=$ transition temperature, FCC to $\mathrm{HCP}$

$\mathrm{T}_{\mathrm{hc}}=$ transition temperature, $\mathrm{HCP}$ to FCC

Figure 6.-Solid hydrogen structural behavior (Ref. 10). The complicated structural behavior of $0.82 \mathrm{p}-\mathrm{D}_{2}$ as a function of temperature.

Solid hydrogen - agglomeration times - 3-23-99

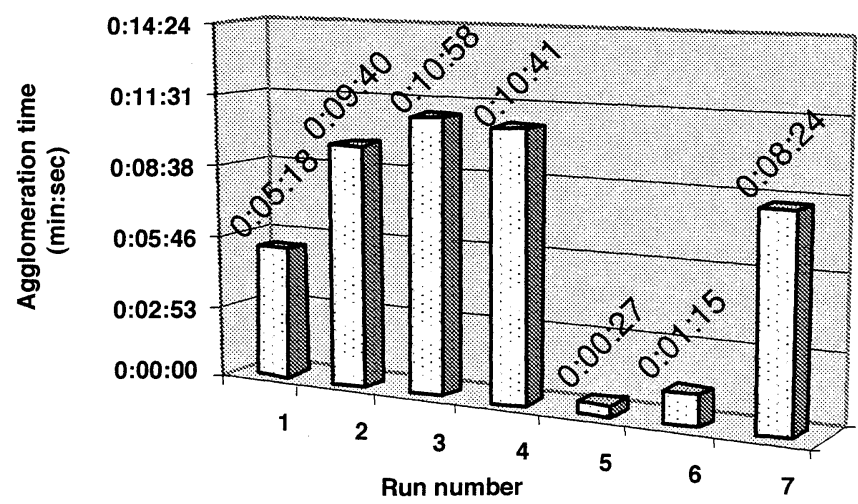

Figure 7.-_Solid hydrogen agglomeration times. 
Solid hydrogen: dewar thermal profile: Run 1-3 - 3/23/1999

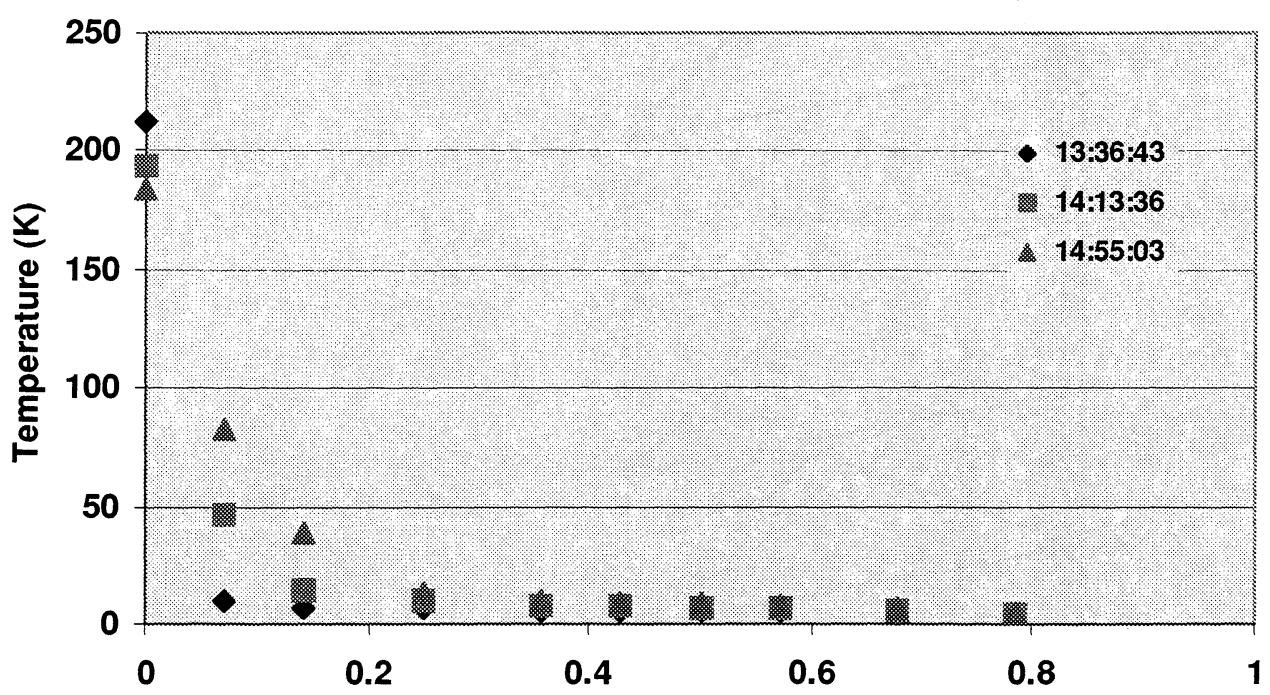

Non-dimensional distance from dewar lid $(x / L)$

Figure 8.-Solid hydrogen temperature profile: runs 1 to 3.

Solid hydrogen: dewar thermal profile: Run 1-3 - 3/23/1999

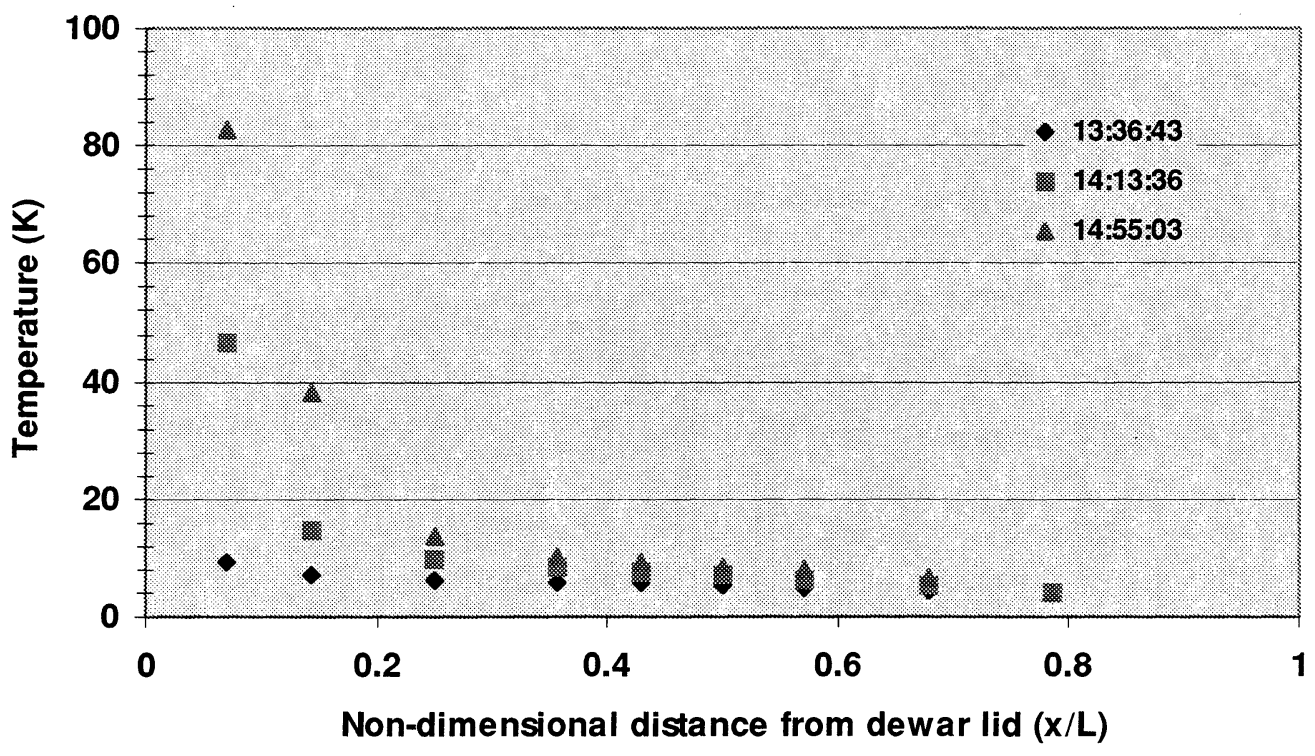

Figure 9.-Solid hydrogen temperature profile: runs 1 to 3 - closeup on low temperature regime. 
Solid hydrogen: dewar thermal profile: Run 4-7, 3/23/1999

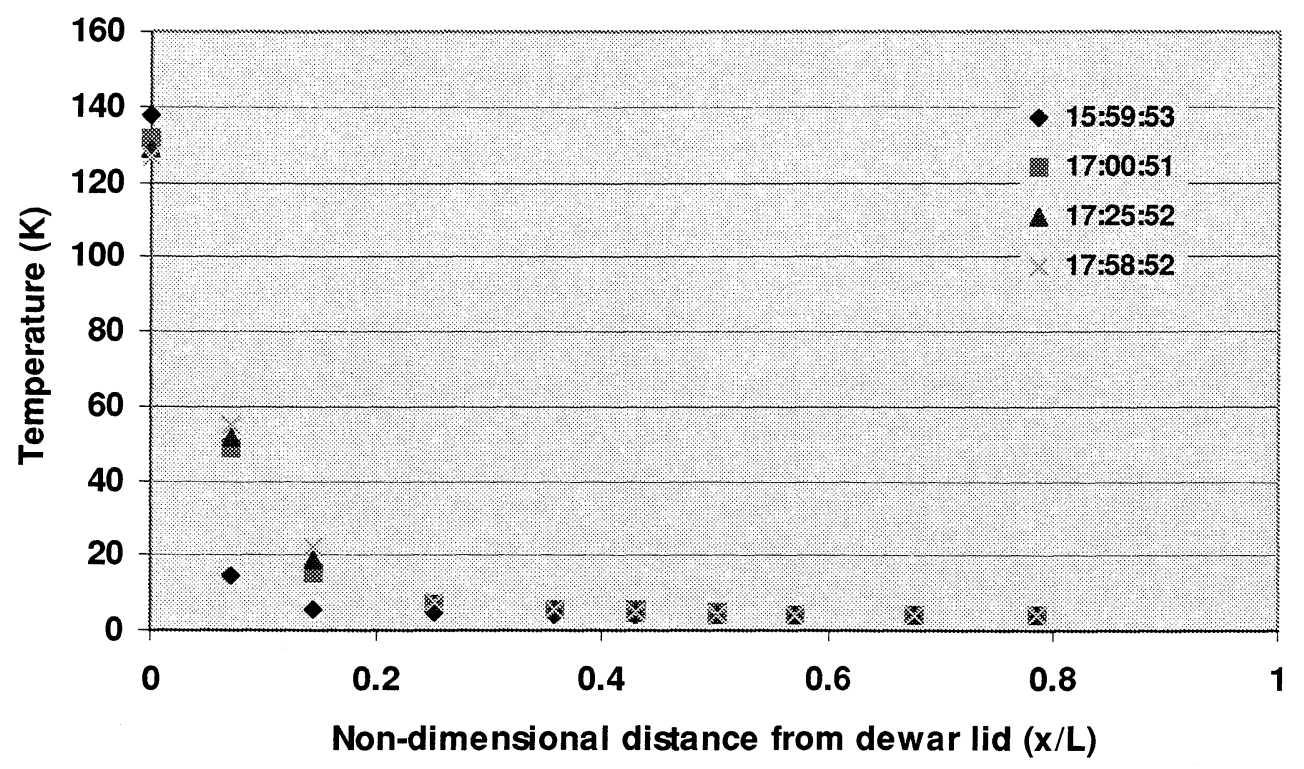

Figure 10. Solid hydrogen temperature profile: runs 4 to 7.

Solid hydrogen: dewar thermal profile: Run 4-7, 3/23/1999

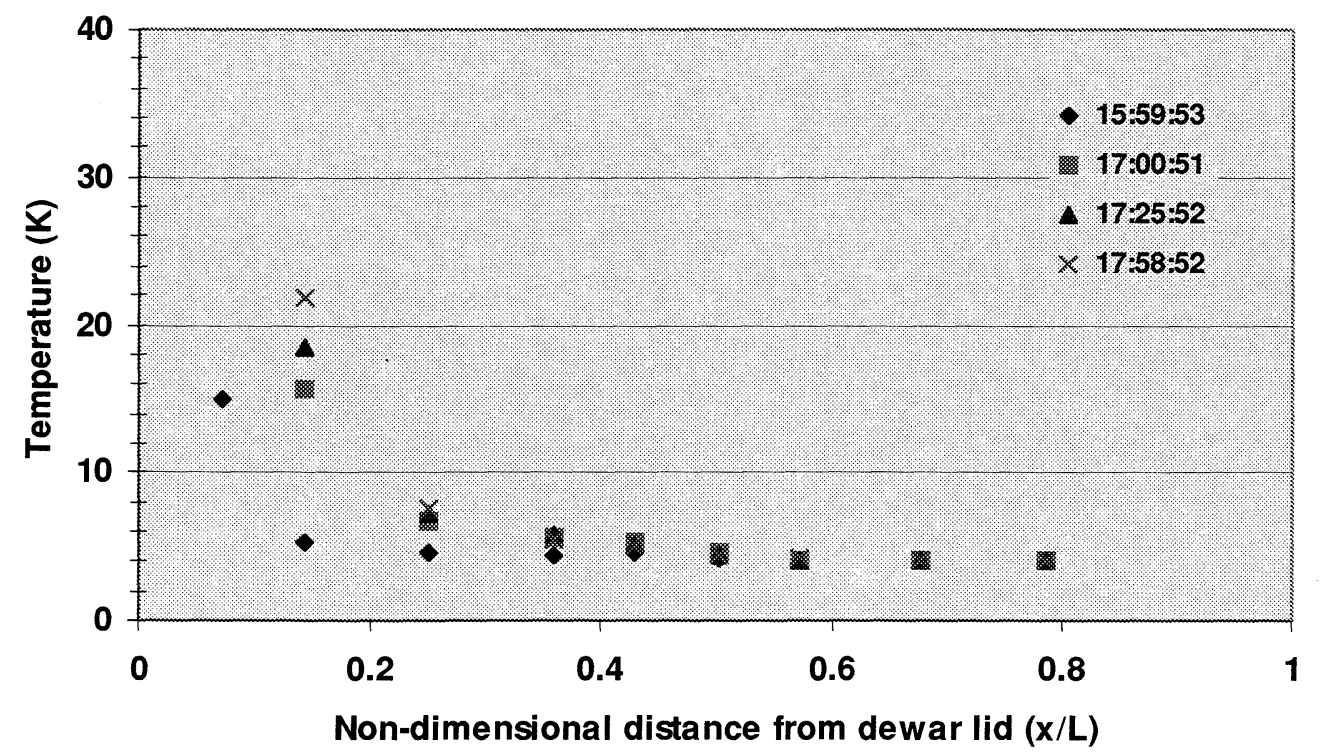

Figure 11. Solid hydrogen temperature profile: runs 4 to 7 - closeup on low temperature regime. 
Page intentionally left blank 


\section{APPENDIX A}

\section{SOLID HYDROGEN VIDEO OBSERVATIONS-DATA SUMMARY TABLE MARCH 23, 1999}

Table A1: Solid hydrogen test summary table

$\begin{array}{ccccc}\text { Run } & \begin{array}{c}\text { Time for start } \\ \text { of test }\end{array} & \begin{array}{c}\text { Hydrogen flow: } \\ \text { on time (s) }\end{array} & \begin{array}{c}\text { Hydrogen temperature } \\ \text { during drop (K) }\end{array} & \begin{array}{c}\text { Liquid helium location } \\ \text { (inches below lid) }\end{array} \\ 1 & 13: 36: 27 & 12 & 19.03 & 19-23 \\ 2 & 14: 13: 35 & 8 & 16.18 & 22 \\ 3 & 14: 55: 02 & 11 & 16.32 & 22 \\ 4 & 15: 59: 34 & 7 & 14.1 & 14-16 \\ 5 & 17: 00: 50 & 8 & 16.17 & 16 \\ 6 & 17: 25: 51 & 13 & 16.13 & 16 \\ 7 & 17: 58: 51 & 46 & 16.87 & 16\end{array}$

\section{VIDEO OBSERVATIONS}

\section{Run 1 or first drop}

Diameter, $\mathrm{FOV}=8.25$ inches

Helium level is between 19 and 20 inches below the lid ( 8 and 9 inches from the bottom).

13:36:27 The 1st drop begins. Solid hydrogen particles form from liquid hydrogen falling into liquid helium bath. The smallest particle sizes are $1 / 16$ to $1 / 8$ inch diameter.

13:36:59 Solid hydrogen agglomerates are a maximum size of 0.25 inches in diameter.

13:41:45 All of the hydrogen has formed into one agglomerated mass. 1 and $1 / 8$ inches by $5 / 8$ inch.

The hydrogen particles are about $1 / 16$ to $18 \mathrm{inch}$ in diameter. They are generally dark in nature, and are not translucent.

13:44:09 The solid hydrogen has formed into a dark mass, with some part being translucent.

13:45:00 The agglomerate of the hydrogen particles has formed an irregularly shaped mass (peanut)
13:46:00 The agglomerate has a roughly circular shape.

13:47:22 The apparatus is shaken to fix a problem and the shaking breaks up the particles.

\section{Run 2 or second drop}

Diameter, $\mathrm{FOV}=8.25$ inches

14:13:35 The 2nd drop begins. A second batch of liquid hydrogen is frozen in the liquid helium. The total mass of hydrogen is roughly 10 times that of the first drop.

14:13:37 The solid hydrogen is already a dark color.

14:13:52 The smallest solid hydrogen particles are $1 / 16$ inch to $1 / 8$ inch in diameter.

14:14:40 The hydrogen particles have formed 2 masses, one 2 and $1 / 8$ inches by 1 and $1 / 4$ inches and one 2 and $1 / 4$ inches by 1 and $1 / 2$ inches. There are lots of particles osculating and creating these masses.

14:14:52 The hydrogen has nearly agglomerated into 1 mass, approximately 2.5 inches in diameter. 
14:14:59 The two masses have still not met and fused. The smallest particles (1/16 inch diameter) are still moving about the 2 masses.

14:16:16 Approximately 20 to 30 percent of the agglomerated hydrogen mass is very translucent and clear, and the rest very dark and much less translucent.

14:23:15 The agglomeration is complete.

14:25:10 The solid hydrogen is all dark, and not translucent any more.

14:25:53 The pressure within the helium dewar is dropped, and the hydrogen agglomerate violently and quickly breaks up into tiny particles.

14:26:00 The smallest particle sizes are 1/16 inch.

14:35:17 A mass at the top of the video frame comes out of the field of view (FOV). It is approximately $1 / 2$ inch out of the FOV.

14:36:27 The particles have agglomerated back into a single mass.

14:50:10 As the mass sits in the liquid helium, there appears to be a shadow surrounding the agglomerate, and it looks like a vapor cloud. It appears at the right hand side of the agglomerate only.

\section{Run 3 or third drop}

Diameter, $\mathrm{FOV}=8.25$ inches

14:55:02 The 3rd drop begins. Gas and particles fall toward the helium surface. The smallest particles are $1 / 16$ inch in diameter.

14:55:03 The particles are very dark and still 1/16 inch in diameter. The view is very cloudy.
14:59:00 A haze of "clear cloud" is present and visible outside of the large agglomerated mass. The agglomerate is about 3.5 inches in diameter.

15:06:00 The agglomeration is complete. The mass is mostly dark, with 10 to 20 percent of the mass being clear.

15:11:26 The mass is about 3 inches in diameter. It is sticking to the rake of silicon diodes.

15:19:58 The pressure is lowered in the helium dewar, and mass of particles violently breaks up into smaller masses. The smallest particle is $1 / 16$ inch, and the largest is a mass about 1 inch in diameter.

15:32:03 There are 2 masses: 1 is dense, and the other is a loose agglomeration.

15:35:12 Helium transfer begins. The agitation during the breakup is less violent than the last breakup event. The particles break up easily.

15:36:04 All of the hydrogen has vaporized.

\section{Run 4 or fourth drop}

Diameter, $\mathrm{FOV}=10.5$ inches

Helium level is between 12 and 14 inches below the lid.

15:59:34 The 4th drop begins. Hydrogen (from the previous tests) forms dark particles in the helium, and they are about 1/16 inch in diameter.

16:07:52 New hydrogen is dropped onto the surface, and the hydrogen forms dark particles (specks) in the helium, and they are about $1 / 16$ inch in diameter.

16:08:19 Particles (specks) move away from the wall. This appears that some of the hydrogen was frozen on the wall, and then fell to the surface. The particle diameters are $1 / 16$ to $1 / 8$ inch. 
16:09:45 Many small and larger agglomerates are forming: $1 / 8$ inch to $1 / 4$ inch.

16:18:33 Agglomeration is complete. The agglomerate size is about 3 times that of Run 1.

16:25:29 There appear to be hydrogen clouds over the liquid helium surface.

16:30:33 Vacuum pump turned on to break up the agglomeration on the surface. Clear and dark particles begin to agglomerate again. The agglomerate sizes are irregular in shape but range from $1 / 16$ inch individual particles to $1 / 2$ inch in size.

16:37:10 The agglomerates are in sizes ranging from $1 / 4$ inch to 1.5 inches. They are composed of particles, $1 / 2$ of the particles are clear and half of them are cloudy.

16:38:50 The agglomerate is now 2 inches in diameter, and the particles are loosely touching each other. The particles are almost all cloudy.

16:47:30 The agglomeration is almost complete, and the particles are still loosely touching each other, with about a 50 percnet void fraction. The agglomerate is 1 inch by 1.5 inches in size.

16:51:06 The agglomeration is now complete.

\section{Run 5 or fifth drop}

Diameter, $\mathrm{FOV}=10.5$ inches

17:00:50 The 5th drop begins. New hydrogen is introduced into the dewar. The particle sizes are from $1 / 16$ inch to $1 / 8$ inch, with the greatest fraction ( 60 percent) being $1 / 8$ inch.

17:01:17 The new particles agglomerate quickly, which is unexpected. The total mass of the agglomerate is about 4 times that of the 4th drop.

17:08:11 There appears to be no edge shadow as was seen in the previous run.

\section{Run 6 or sixth drop}

Diameter, $\mathrm{FOV}=10.5$ inches

17:25:51 The 6th drop begins. The new particles are $1 / 16$ inch in diameter. Most of the hydrogen falls on the previous agglomerate.

17:26:54 There is a significant amount of cloudiness in the view, and many particles have formed. The agglomerate mass is 2 times the mass of that from Run 5.

17:27:06 The agglomeration is complete.

17:29:00 The agglomeration is becoming denser, and it is darker on the outside, with lighter patches on the inside. The mass is an elliptical shape about 2 by 3.5 inches.

The mass is moving in a circular motion, with particles exchanging position within the agglomerate, but the particles are still osculating. The mass remains in the upper right quadrant of the view.

17:51:45 The agglomerate is coalescing further, and its size is now 2 inches by 2.5 inches, with an elliptical shape.

\section{Run 7 or seventh drop}

Diameter, $\mathrm{FOV}=10.5$ inches

17:58:51 The 7th drop begins. The particle sizes are $1 / 16$ inch in diameter.

17:58:58 The particle sizes are 1/16 inch and 1/8 inch in diameter.

17:59:30 The view is foggy in the dewar. The agglomeration is continuing.

17:59:43 View is VERY foggy in the dewar.

18:01:57 Agglomeration is complete, but the hydrogen is not transparent or clear. The view is terribly foggy from gas in the dewar. 
18:03:00 Fog is clearing. The agglomerate is 3 to 4 times the size of the Run 6 agglomerate.

18:07:15 Fog is much clearer. The agglomerate looks like a pancake: 4 by 4.5 inches.

18:25:36 Pressure is reduced in the dewar, and the particles break up. After the break up, the particles are 1/16, 1/8, and 1/4 inch in size.

18:28:00 The surface is quiescent, and the particles seem to be forming a gellant structure on the surface. The particles are spread out over the surface, but still osculating.

18:30:59 The two large sets of particles touch one another, forming a gel-like structure over the helium surface.
18:33:00

Almost all of the particles have agglomerated or are touching one another. The surface is very quiet. There are few or no disturbances.

18:39:06 Helium is being evacuated from the dewar. Clouds are created during the evacuation.

18:42:37 A mass of material that looks like a set of tentacles is in the upper right quadrant of the view (this may be frozen hydrogen).

18:44:37 The tentacled mass breaks off and drops into the void. 


\section{APPENDIX B}

SOLID HYDROGEN VIDEO IMAGES: MARCH 23, 1999

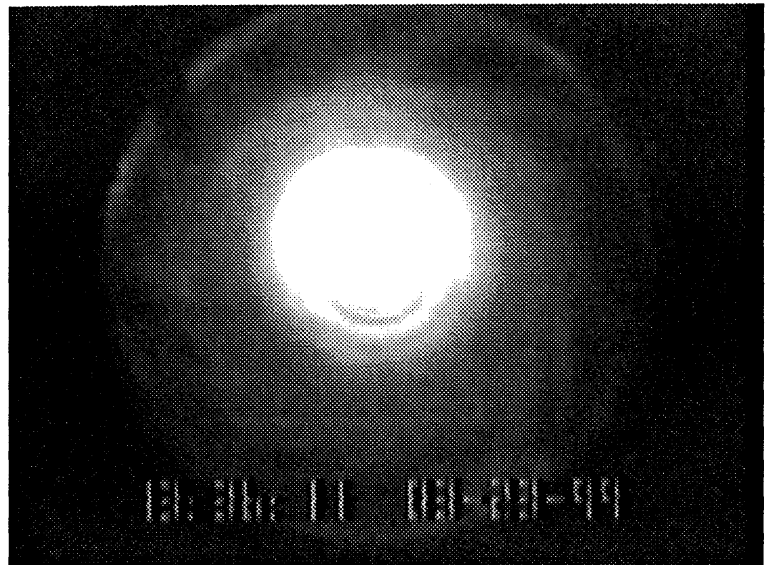

Figure B1. Solid hydrogen images: 3/23/1999 - 13:36:11.

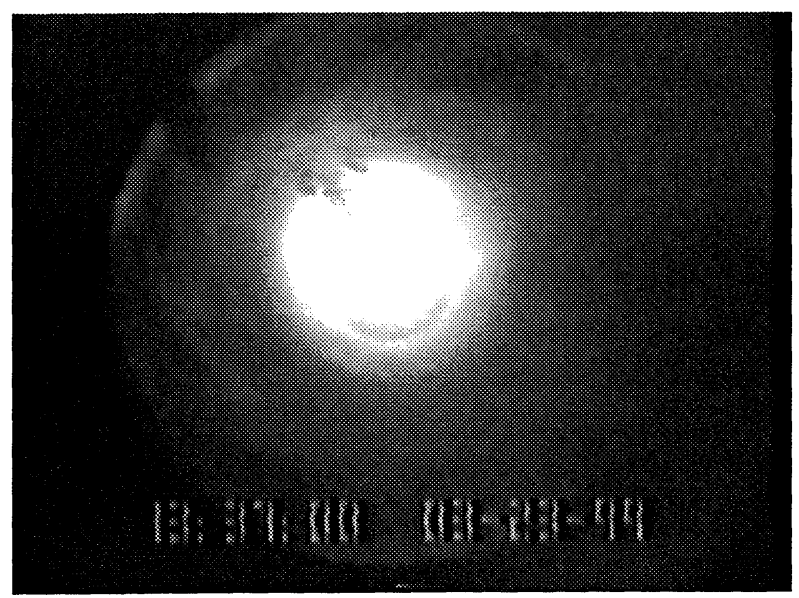

Figure B2.-Solid hydrogen images: 3/23/1999 - 13:37:00.

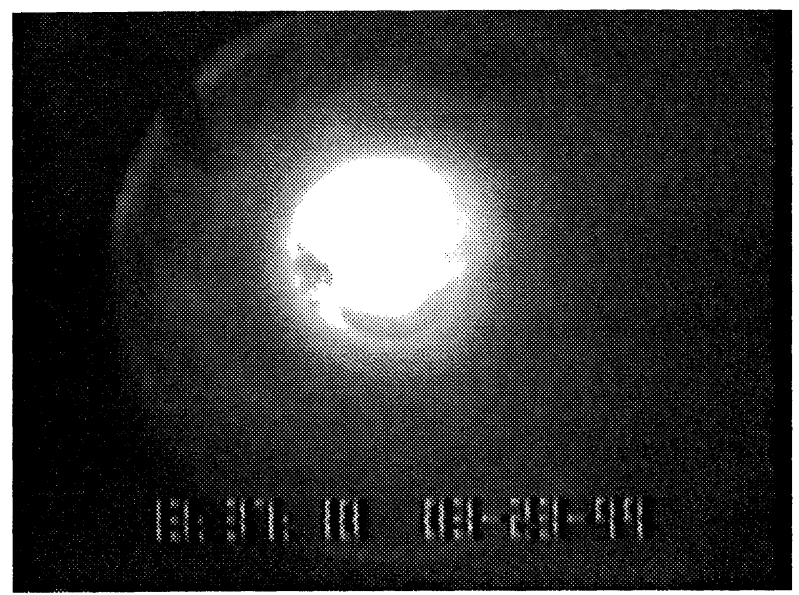

Figure B3. Solid hydrogen images: 3/23/1999 - 13:37:10. 


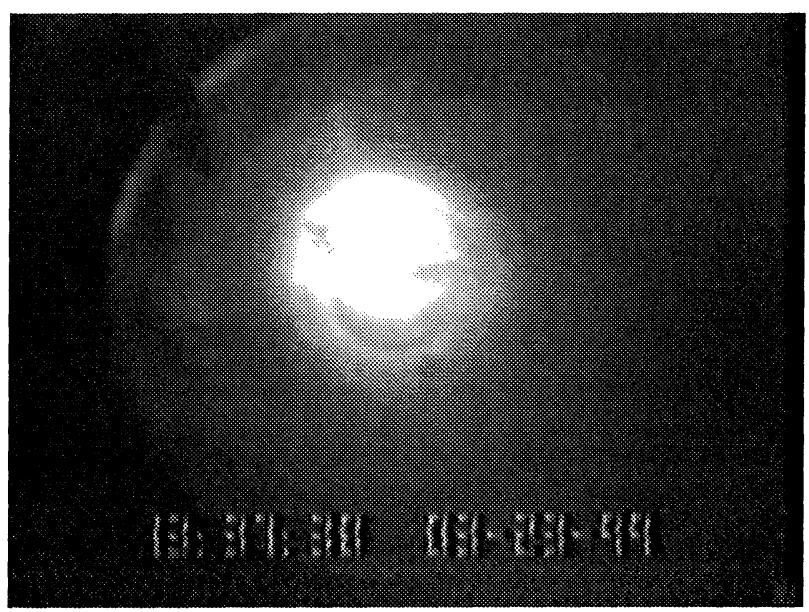

Figure B4. - Solid hydrogen images: 3/23/1999 - 13:37:38.

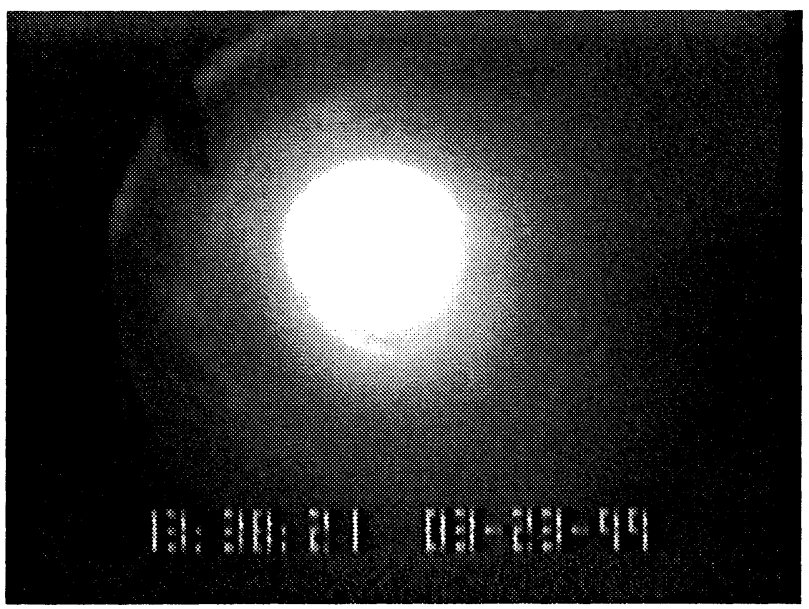

Figure B5.-Solid hydrogen images: 3/23/1999 - 13:38:21.

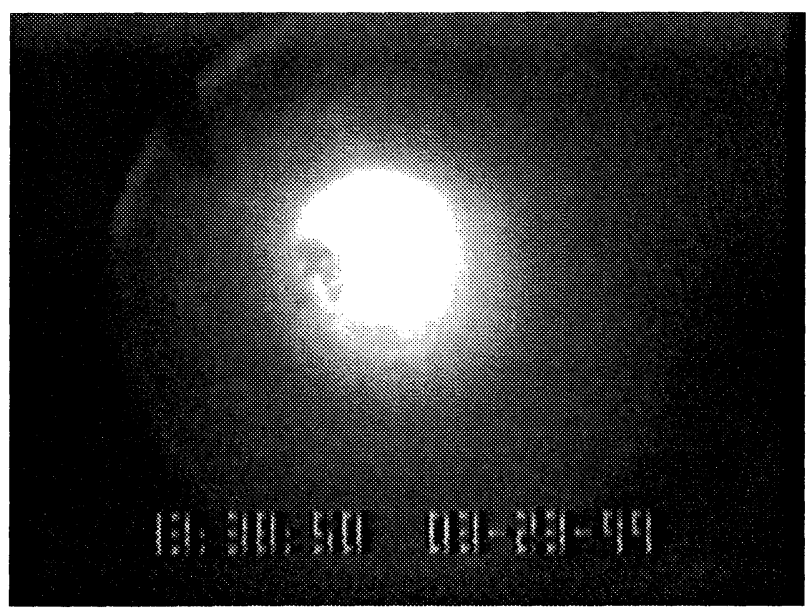

Figure B6. Solid hydrogen images: 3/23/1999 - 13:38:50. 


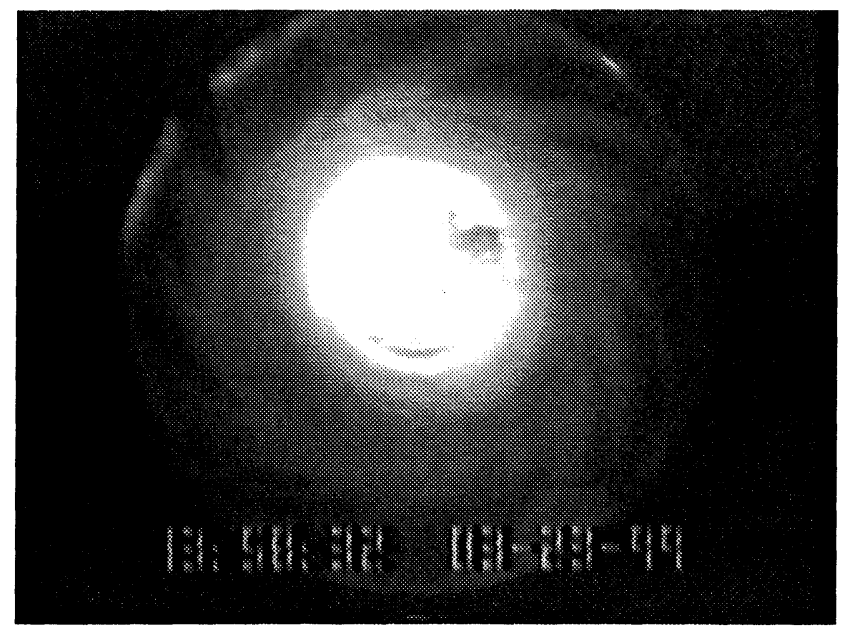

Figure B7. Solid hydrogen images: 3/23/1999 - 13:58:32.

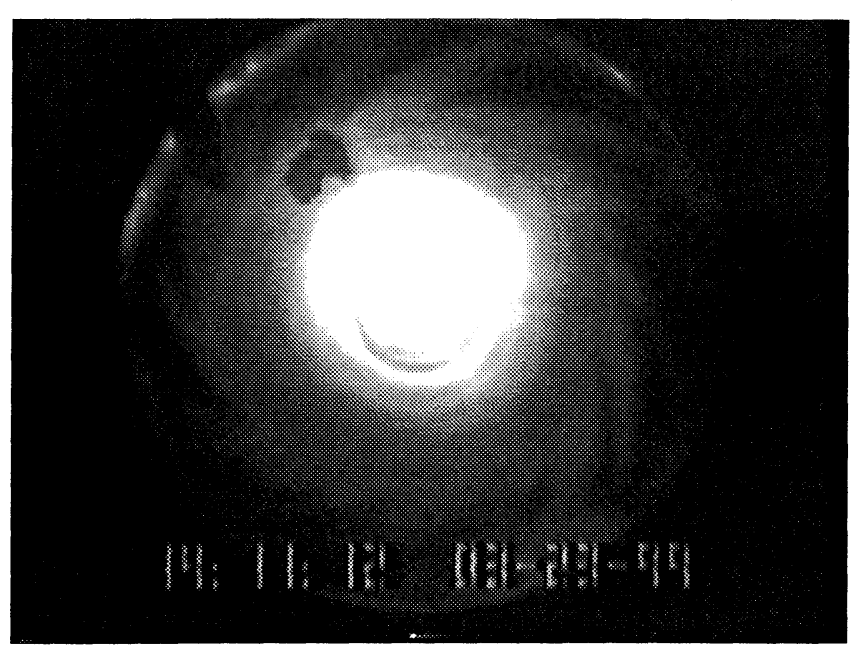

Figure B8. - Solid hydrogen images: 3/23/1999 - 14:11:12.

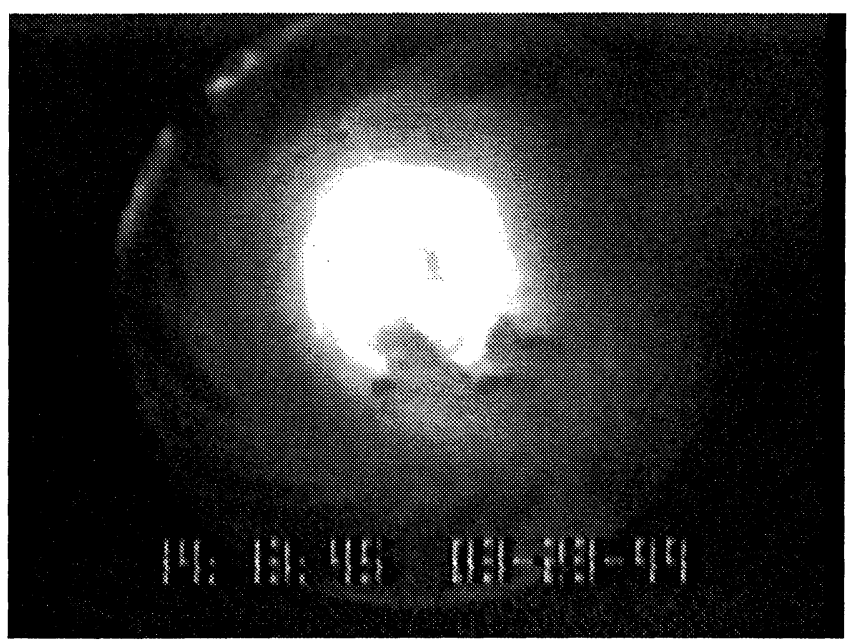

Figure B9.-Solid hydrogen images: 3/23/1999 - 14:13:45. 


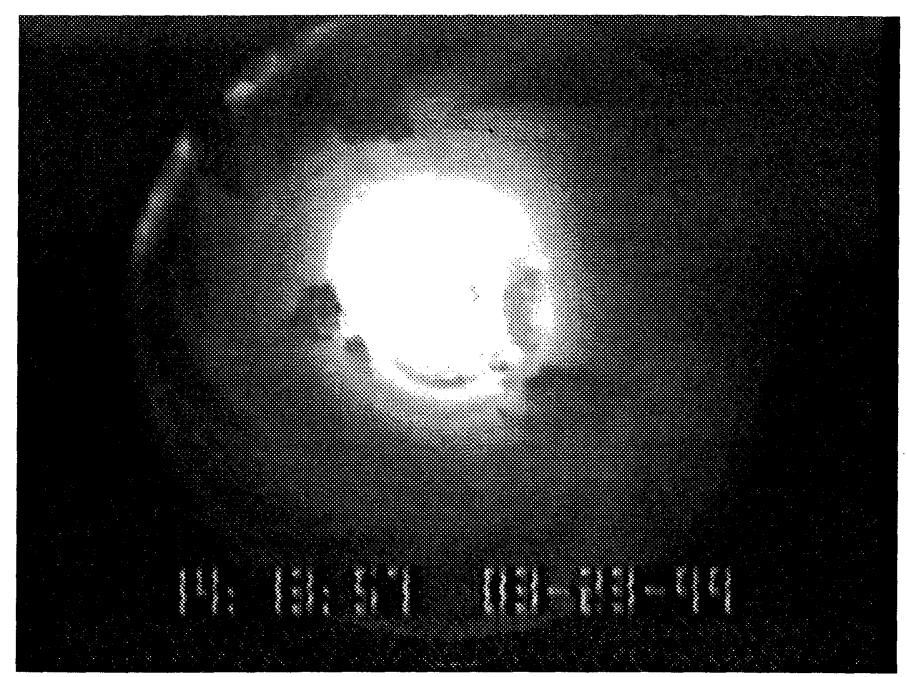

Figure B10.—Solid hydrogen images: 3/23/1999 - 14:13:57.

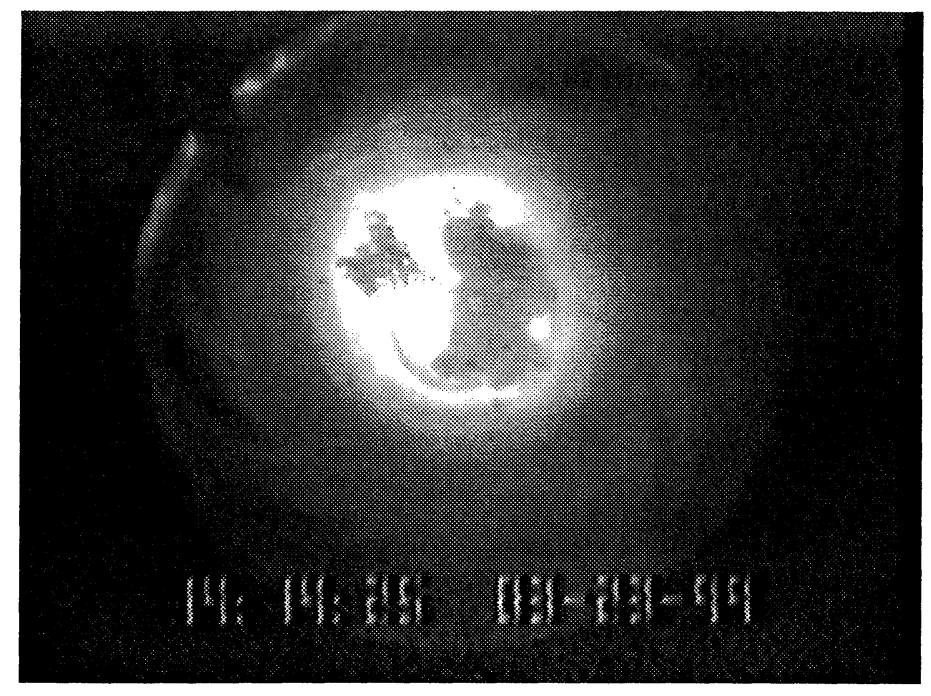

Figure B11_ - Solid hydrogen images: 3/23/1999 - 14:14:25. 
Public reporting burden for this collection of information is estimated to average 1 hour per response, including the time for reviewing instructions, searching existing data sources, gathering and maintaining the data needed, and completing and reviewing the collection of information. Send comments regarding this burden estimate or any other aspect of this Davis Highway, Suite 1204, Arlington, VA 22202-4302, and to the Office of Management and Budget, Paperwork Reduction Project (0704-0188), Washington, DC 20503.

\begin{tabular}{|l|c|c|c|}
\hline 1. AGENCY USE ONLY (Leave blank) & $\begin{array}{r}\text { 2. REPORT DATE } \\
\text { December } 2001\end{array}$ & $\begin{array}{r}\text { 3. REPORT TYPE AND DATES COVERED } \\
\text { Technical Memorandum }\end{array}$ \\
\hline 4. TITLE AND SUBTITLE & $\begin{array}{r}\text { 5. FUNDING NUMBERS } \\
\hline\end{array}$
\end{tabular}

Solid Hydrogen Experiments for Atomic Propellants

6. AUTHOR(S)

WU-713-74-10-00

Bryan Palaszewski

7. PERFORMING ORGANIZATION NAME(S) AND ADDRESS(ES)

National Aeronautics and Space Administration

John H. Glenn Research Center at Lewis Field

Cleveland, Ohio 44135-3191

8. PERFORMING ORGANIZATION REPORT NUMBER

E-13095

9. SPONSORING/MONITORING AGENCY NAME(S) AND ADDRESS(ES)

10. SPONSORING/MONITORING

National Aeronautics and Space Administration

Washington, DC 20546-0001 AGENCY REPORT NUMBER

NASA TM-2001-211292

AIAA-2000-2855

11. SUPPLEMENTARY NOTES

Prepared for the 36th Joint Propulsion Conference and Exhibit cosponsored by the AIAA, ASME, SAE, and ASEE

Huntsville, Alabama, July 16-19, 2000. Responsible person, Bryan Palaszewski, organization code 5830, 216-977-7493.

12a. DISTRIBUTION/AVAILABILITY STATEMENT

12b. DISTRIBUTION CODE

Unclassified - Unlimited

Subject Categories: 15, 20 and 28

Distribution: Nonstandard

Available electronically at http://gltrs.grc.nasa.gov/GLTRS

This publication is available from the NASA Center for AeroSpace Information, 301-621-0390.

13. ABSTRACT (Maximum 200 words)

This paper illustrates experiments that were conducted on the formation of solid hydrogen particles in liquid helium. Solid particles of hydrogen were frozen in liquid helium, and observed with a video camera. The solid hydrogen particle sizes, their molecular structure transitions, and their agglomeration times were estimated. article sizes of 1.8 to $4.6 \mathrm{~mm}$ ( 0.07 to $0.18 \mathrm{in}$.) were measured. The particle agglomeration times were 0.5 to $11 \mathrm{~min}$, depending on the loading of particles in the dewar. These experiments are the first step toward visually characterizing these particles, and allow designers to understand what issues must be addressed in atomic propellant feed system designs for future aerospace vehicles.

14. SUBJECT TERMS

Cryogenic fuels; Atomic fuels; Atoms; Gelled rocket propellants 15. NUMBER OF PAGES 28

16. PRICE CODE

\section{SECURITY CLASSIFICATION OF REPORT}

Unclassified

18. SECURITY CLASSIFICATION
OF THIS PAGE
Unclassified

19. SECURITY CLASSIFICATION OF ABSTRACT Unclassified 